\title{
Development of Automated Control System for Kuih Penderam Stamping Machine
}

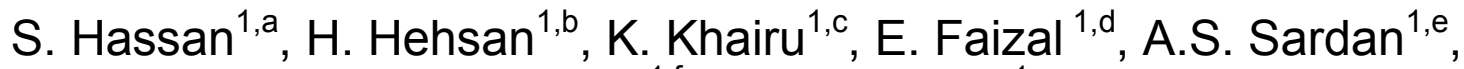 \\ N.A. Salim ${ }^{1, f}$ and A. Kasmin ${ }^{1, g}$ \\ ${ }^{1}$ Faculty of Mechanical and Manufacturing Engineering, Universiti Tun Hussein Onn Malaysia, \\ 86400 Batu Pahat, Johor, Malaysia \\ asuhaimihas@uthm.edu.my, bhaffiz@uthm.edu.my, ckhairu@uthm.edu.my, \\ dfaizalesa@uthm.edu.my, eainsyuhada.fpga@gmail.my, ${ }^{\mathrm{f}}$ nuraisyah.abdulsalim@gmail.my, \\ gasyari@uthm.edu.my
}

Keywords: Production Time, Control System, Reliability Analysis

\begin{abstract}
It is essential to design a control system for stamping process in Kuih Penderam production. The main problem is how to produce the Kuih Penderam due to high demand but low in energy consumption. The objective of this study is to convert the system of Kuih Penderam stamping process from manual system to automatic system. The system is consists of the software and components to be used. There are few components that have been use on designing the automatic system which is PLC systems, compressor, sensors, connectors and push buttons. The results of the reliability for the system shows that all the LED lights are function when the signal is connected to the PLC system on the circuit in a direct connection. This case show every components testing is working properly.
\end{abstract}

\section{Introduction}

This research was done to help the process of stamping Kuih Penderam that can be more effectively and save labor. There are several challenges that must be faced. The challenge is to ensure that the new development of Kuih Penderam machine in reducing the energy consumption. The control system is designed to be more effective in terms of production time. This is because a producer could achieve a high production rate besides of saving a labor cost by using this new invention. Current method used is too manually which are requires a high number of trained worker which unable to achieve high production rate. Therefore to reduce the cost of labor intensive, the machine was designed to replace the manual method to an automatic machine.

Small and Medium (SME) Industry in Batu Pahat area produces Kuih Penderam by using manual stamping method. There are a few things that can be discussed on manual and automatic stamping process. Both methods have their advantages and disadvantages towards the making process. In a manual stamping process, it does not require an operating cost and high control system, no maintenance requires, easy to handle and does not required skill worker with high salary. But, it require high energy consumption, using a lot of time to complete the demand, sometimes they can't reach the production target pertime and uneven result produce due to human mistakes.

In automatic stamping process, it will produce a quality product in terms of hygiene and safety. It can increase the production rate because this machine can reach the target in time. It also can reduce the human energy consumption and not require high skill workers. The product must be better than previously method because this machine does not involve human mistakes. For disadvatages, it requires high cost preparation and handling, high skill worker due to frequently maintenance and require large working layout for operation control.

According to Chapman [1], automated means design, build and implement an automatic machine. The machine that can produce a lot of volume and quality products to reduce costs is the dream of every engineers. To produce control systems for Kuih Penderam machine, machine design is the first step in designing so that all components can work properly after admission control systems. 
Automation system is the design of control systems and components to produce the desired product [2]. To create an automated machine, the first thing is electrical and mechanical components are in order to improve with every movement of machine automation. Pneumatic systems are power systems using compressed air as a working medium for the power transmission. An air compressor converts the mechanical energy of the prime mover into mainly, pressure energy of the compressed air [3]. Its commonly plumbed with compressed air or compressed gases. This is because a centrally located and electrically powered compressor that powers cylinders and other pneumatic devices through solenoid valves. Its can often provide motive power in a cheaper, safer, more flexible and more reliable way than a large number of electric motors and actuators.

Other researcher said that the process begin with a programmable logic controller (PLC), it will get an input signal from the computer and then convert to become warning signal. From the warning signal, it will go through a customer responds. A water pumping control system with PLC system and IWLAN research explain another function of the PLC system in the control system. The PLC will send a digital signal to the water pump to turn it on or off, based on the tank level of the water in the tank. IWLAN stand for industrial wireless local area network. IWLAN used as a communication connection in the process [4].

Environmental factors also need to be aware because when the environment is not conducive to render the employee unable to work comfortably and would result in an ergonomic environment is negligible. Ergonomic design using information on the movement of people is to create objects, facilities and atmosphere for human consumption [5].

Therefore, this research was focused on design of the machine control system of Kuih penderam for automated stamping process based on electro-pneumatic system. The test had been perform to determine whether the system is designed can be used or not.

\section{Research Methodology}

Controller Design and Simulation. Automation Studio is an innovative system design, simulation and project documentation software solution for the design and support of automation. It is the most effective engineering software for schematic design, component sizing, circuit simulation, engineering documentation, prototyping, testing and troubleshooting [6]. The research was used this software to simulate and troubleshoot the pneumatic system that had be done. The software provides all the necessary tools to let users create their own symbols and configure simulation models. It provided via user-friendly interfaces that allow to design directional valves, actuators and motors.

CX-Programmer Analysis. CX-Programmer software was used to write program or ladder diagram [6]. The program was transfer from computer to Programmable Logic Controller (PLC) device. The diagram workspace can display a ladder program, the symbol table of that program or the Mnemonic view. The details displayed depend upon the selection made in the project workspace. When a new project is created or a new PLC added to a project, an empty ladder is automatically displayed on the right-hand side to the project workspace. The symbol table and Mnemonics view must be explicitly selected to be displayed. All views can be opened at the same time and can select via option associated with the window menu. PLC program instruction can be entered as a graphical representation in ladder form. Programs can be created, edited, and monitored in this view.

Automation and Electrical Analysis. Pneumatic systems are used compress air as a working medium for the power transmission. In this research, the machine used pneumatic to move the cylinder. After all the information is collected, the controller system design of an automatic stamping machine started. The analysis is performed on the model that has been built and installed which two double acting cylinders must be controlled. In addition, the cylinder is controlled by a single solenoid and double solenoid varying sizes. The solenoid is controlled by the program has been set up on the PLC. Each cylinder has a different task and control that very important in this 
system. The cylinder is a component that will move a particular part at that particular time. Each cylinder movement will also be influenced by time and sensor set to suit the area.

Circuit wiring PLC was made after the program control system has successfully passed. PLC connection or wiring circuit is the result of a preliminary analysis of the control system. Circuit is the link between the components of the PLC being used. The circuit also includes pneumatic and electrical components. Each component of the output and the input to the circuit PLC has the address specified on the ladder diagram. If the wiring in the circuit is not in accordance with a predetermined address, operating system will not operate.Wiring can be done in short if there is no problem on the components used. This analysis is intended to ensure that the control system can be constructed and operated in accordance with a predetermined plan.

Test of the movement focused on moving the cylinder mechanism stamping machines. This test is performed to determine the most appropriate time of the control system that was done on the cylinder. The testing process was done after the PLC program had been transfer and works well. Time was set on the program and exchanged for the testing process.

\section{Results and Discussion}

Reliability Analysis. For the development of this system, PLC system reliability test analysis is important because one of the main objectives is to test the system to ensure they are operating properly. Each component in the PLC system is successfully tested using a multimeter and circuit direct connection. Ladder Diagram PLC system is done using CX-Programmer and simulation is done using Automation Studio software.
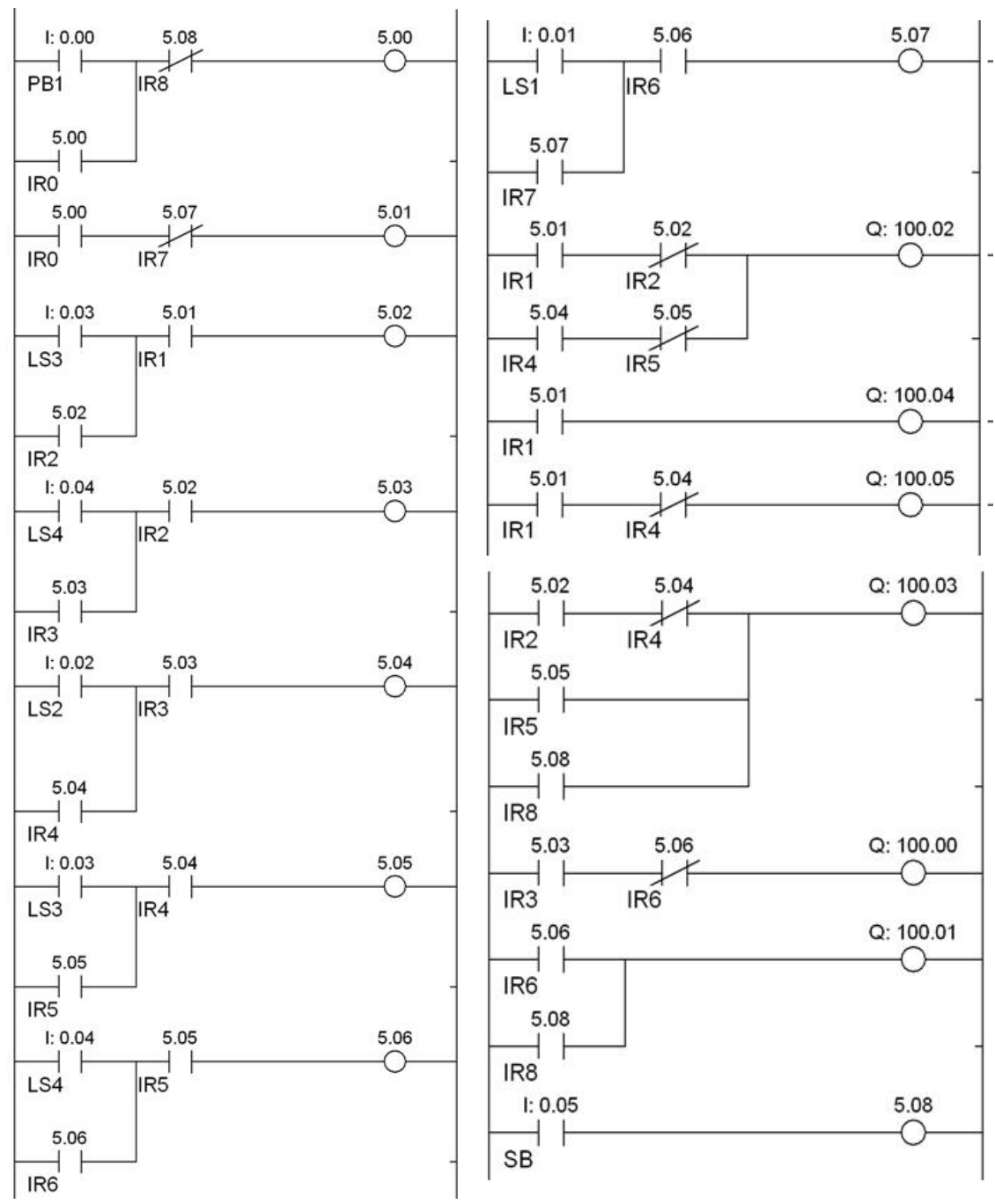

Fig.1 Ladder Diagram for development of stamping process in Kuih Penderam 
PLC system test plays a very important role in determining whether a PLC system can work or not. The researcher also is able to take the data and information necessary after conducting tests on the system PLC. Ladder Diagrams produced has given a proven and successful implementation to be sent to the actual PLC and it can be used to control systems for the production of Kuih Penderam. Fig. 1 shows the tested Ladder Diagram by using the CX-Programmer.

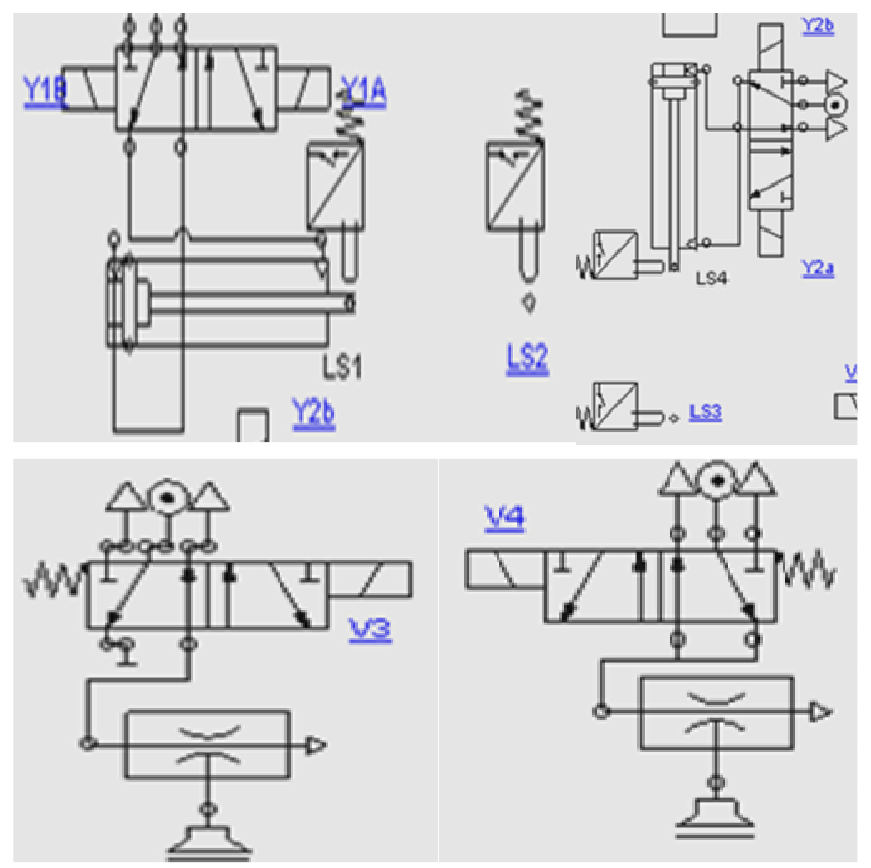

(a)Pneumatic diagram of each cylinder and vacuum

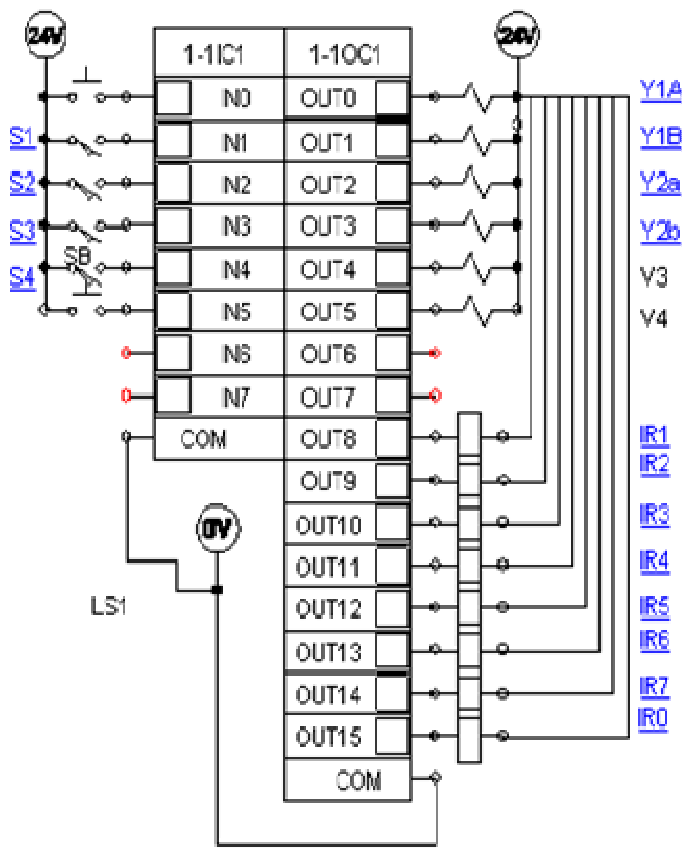

(b) Electrical diagram

Fig. 2 Simulation result by Automation Studio software

Automation Studio Result. Automation Studio software was applied in the design, training and troubleshooting of pneumatics and electrical control systems. In this software, a ladder diagram from CX-Programmer, pneumatics diagram and electrical diagram was designed. From that, simulation was done by testing pneumatics diagram referred to the ladder diagram and electrical diagram. The system had been troubleshooted before starting wiring process based on the pneumatic diagram that has been created. Simulation process by using Automation Studio software includes a pneumatic diagram of each cylinder and vacuum and also electrical diagram that shown in Fig. 2.

Table 1 Data for production time against automatic and manual stamping process

\begin{tabular}{|c|c|c|c|c|c|c|c|c|c|c|c|}
\hline \multirow{2}{*}{$\begin{array}{c}\text { No. of } \\
\text { mixture }\end{array}$} & $\begin{array}{c}\text { Cyl. } \\
\text { B } \\
\text { extent }\end{array}$ & $\begin{array}{c}\text { Cyl. } \\
\text { B } \\
\text { reset }\end{array}$ & $\begin{array}{c}\text { Cyl. } \\
\text { A } \\
\text { extent }\end{array}$ & $\begin{array}{c}\text { Cyl. } \\
\text { B } \\
\text { extent }\end{array}$ & $\begin{array}{c}\text { Cyl. } \\
\text { B } \\
\text { reset }\end{array}$ & $\begin{array}{c}\text { Cyl. } \\
\text { A } \\
\text { reset }\end{array}$ & $\begin{array}{c}\text { Total } \\
\text { time } \\
\text { taken }\end{array}$ & $\begin{array}{c}\text { Stamping } \\
\text { the outer } \\
\text { shape }\end{array}$ & $\begin{array}{c}\text { Stamping } \\
\text { the inner } \\
\text { shape }\end{array}$ & $\begin{array}{c}\text { Place } \\
\text { on } \\
\text { tray }\end{array}$ & $\begin{array}{c}\text { Total } \\
\text { time for } \\
\text { stamping }\end{array}$ \\
\hline 1 & 1 & 1 & 1 & 1 & 1 & 1 & 6 & 8.2 & 14.62 & 16.61 & 39.43 \\
\hline 2 & 1 & 1 & 1 & 1 & 1 & 1 & 6 & 6.89 & 10.8 & 12.27 & 29.96 \\
\hline 3 & 1 & 1 & 1 & 1 & 1 & 1 & 6 & 6.31 & 10.78 & 13.13 & 30.22 \\
\hline 4 & 1 & 1 & 1 & 1 & 1 & 1 & 6 & 6.39 & 8.02 & 12.39 & 26.8 \\
\hline 5 & 1 & 1 & 1 & 1 & 1 & 1 & 6 & 5.42 & 8.75 & 11.8 & 25.97 \\
\hline 6 & 1 & 1 & 1 & 1 & 1 & 1 & 6 & 5.41 & 8.34 & 11.19 & 24.94 \\
\hline 7 & 1 & 1 & 1 & 1 & 1 & 1 & 6 & 4.75 & 7.67 & 10.64 & 23.06 \\
\hline \multicolumn{10}{|c|}{ Average time taken (automatic) } & 6 & \multicolumn{3}{c|}{ Average time (manual) } & 28.63 \\
\hline
\end{tabular}

Time Taken Result. Several tests had been done to analyse a comparison of production time for manual and automated stamping system. Movement test focused on moving the cylinder mechanism for the stamping machine. This test was performed to determine the most appropriate time of the control system on the cylinders. A time have been recorded depends on the process took 
place. Each test was done for a 7 times to get the accurate value of time taken. Table 1 showed the data for production time against automatic and manual stamping process takes place for one cycle stamping process. From Table 1, a graph has been constructed to compare a production time taken for both methods as shown in Fig. 3. From the graph shown, time taken for manual stamping process is higher than automated stamping process which is $6.0 \mathrm{~s}$ for automatic method and $29.0 \mathrm{~s}$ for manual method. This data has proved that manual method takes a long time to achieve a high demand of production.

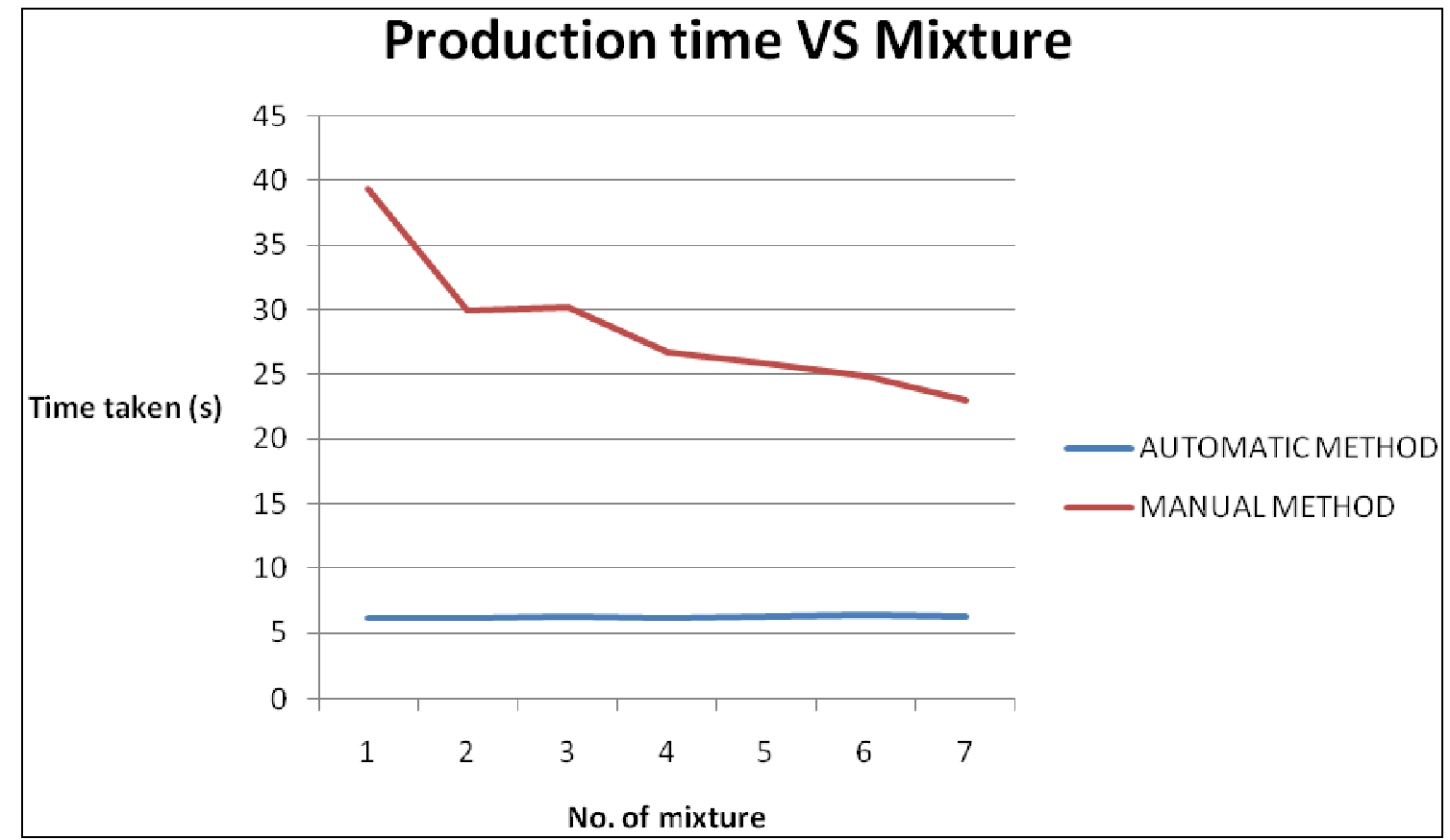

Fig. 3 Comparison of production time for manual and automatic method

\section{Conclusion}

As a conclusion:

i. Reliability test is important to test the controller system to ensure they are operating properly method.

ii. Production time for automatic method is better than manual method.

iii. This study indicates the important of controller system in producing a Kuih Penderam stamping machine that can improve and reduce the production time.

\section{References}

[1] S. J. Chapman. Electrical Machinery Fundamental, Mc Graw Hill International Edition, 2005.

[2] S. Gulpanich, V. Tipsuwanporn, T. Suesut, K. Tirasesth, An Emphasis on Design and Applications, IEEE Trans. Ind. Electron. 46 (2006).

[3] S. Maeda, N. Tsujiuchi, T. Koizumi, M. Sugiura, H. Kojima, Development and Control of a Pneumatic Robot Arm for Industrial Field, IEEE International Conference on Industrial Technology. 9 (2012) 59.

[4] R. Bayindir, Y. Cetinceviz, A water pumping control system with a programmable logic controller (PLC) and industrial wireless modules for industrial plants, ISA Transaction. 50(2011) 321-328.

[5] P. J. Deiter, S. S. Nocholls, L. A. Pearlman, Self-injury and self capacities: Assisting an individual in crisis, Journal of Clinical Psychology. 56 (2000) 1173-1191.

[6] A.R. James, J.S. Glenn. Programmable Logic Controllers, Pearson Prentice Hall, Library of Congress Cataloging in Publication Data, 2007. 